\title{
Who ate all the pies? The importance of food in the Australian sporting experience
}

Keith D. Parry, Timothy Hall, Alastair Baxter

Address correspondence:

Keith D. Parry

Bournemouth University

Email: kparry@bournemouth.ac.uk

Timothy Hall

Western Sydney University

School of Business, Locked Bag 1797, Penrith South DC, NSW 1797

t.j.hall@westernsydney.edu.au

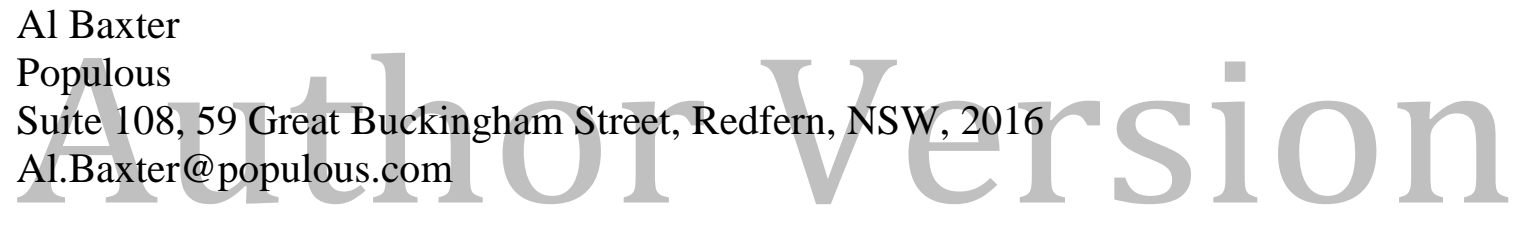




\title{
Who ate all the pies? The importance of food in the Australian sporting experience
}

\begin{abstract}
Australians watch live sport in large numbers and traditionally consume high quantities of meat pies, chips and beer within stadiums. However the food and beverage preferences of stadium-attending Australian sports fans are not well understood, particularly in comparison to their North American and European peers. This paper utilised a survey-based approach to understand the satisfaction of fans of Australia's national Rugby Union team with stadiums in Australia. While food and beverage offerings were found to be a particular point of dissatisfaction the price and service quality were found to be of greater concern than the healthiness of these. The study also drew on the researchers' observations and knowledge of recent Australian stadium redevelopments to examine how the traditional offerings may be changing. We conclude that in order to attract greater attendances from a wider market, stadiums in Australia need to provide more varied, higher quality, healthy food and beverage offerings that are both affordable and easy to eat.
\end{abstract}

Keywords: stadiums; food; food and beverage; sports fans; fan experience; healthy stadia

\section{Introduction}

Every year over two-fifths of Australians aged 15 and over attend a sporting event. This equates to almost 8 million adults attending each year (ABS 2012). However, while the average 2012 attendance figure for the Australian Football League (AFL) was almost 33,000 attendees per match the figures in other Australian sporting codes does not match this number (Sporting Intelligence 2013). For instance, the average figure in the National Rugby League (NRL) was only 16,423, which falls some way short of the National Football League (NFL) (68,278), German Bundesliga (43,331), English Premier League $(36,464)$, and the Major League Baseball for example (30,517) (Barrett 2016). Indeed German Association Football team Borussia Dortmund averaged 80,451, NFL American 
Football team Dallas Cowboys 88,531, and NCAA American Football team Michigan 112,252 fans per match in 2012 (Sporting Intelligence 2013). With the amount of sport available on television increasing (Rowe \& Scherer 2014), Australian sports teams may find it increasingly difficult to encourage an increasingly sedentary population to attend live events, especially if compounded by additional negative factors such as poor quality food and beverage at the stadium venues. This inactivity creates an interesting social obligation on professional sporting bodies to not only use sport as a spectacle for television, but to also encourage fans to be an active part of a healthier, sport inspired lifestyle (Parnell et al. 2015; Inoueet al. 2015; Anagnostopoulos 2012).

Academic studies into attendance and/or spectator satisfaction at sports events have been conducted across a number of continents, including North America, Europe, Asian, and Australasia, and in a number of sports, including golf, American football, basketball, association football and rugby league. Bouchet et al. (2011) argue that sports spectators share common characteristics and so it is possible to compare spectators across sports, time, and location. Analyses of these studies have revealed a number of factors influencing attendance at sporting events. In a Spanish setting it was found that attendance at sporting events was linked to social class (Lera-López, Ollo-López, \& Rapún-Gárate 2012). Those spectators of middle and high social class, with average to high level of education and socio-economic status, had higher levels of attendance at professional sporting events. Gender differences have also been identified in the experiences of sports spectators. Men were more likely than women to evaluate the performance of athletes competing in the sport while fantasising that they were a part of the action. In such a way men would achieve a sense of flow during sporting competitions. Conversely women were more likely to appreciate the aesthetic beauty of the sport performance, by either men or women, and to evaluate the performance of athletes (Madrigal 2006).

There are many factors that influence a person's decision to attend a sporting event, such as price, transport, and availability of competing leisure activities. One factor, which has been examined in some detail, is that of the stadium itself. A number of studies found that the physical environment of a sports stadium influenced attendance (Hill \& Green 2000; Wheaton 2004; Yusof \& Lee 2008), however, there is also need for research 
into the less tangible elements of the sporting experience. Similarly, in Australia there are a range of influences which impacts on the less tangible elements of the sporting experience. This paper considers the importance of food in the Australian sporting context using a case study of fans of Australia's national Rugby Union team (commonly referred to as the Wallabies).

\section{At the stadium}

Once at a venue perceptions of service quality will impact on a non-avid spectator's satisfaction, which in turn influences re-patronage intentions (Wakefield \& Blodgett 1996) as spectators who enjoy spending time at the stadium are inclined to return to the stadium for future games (Wakefield \& Sloan 1995; Greenwell, Fink \& Pastore 2002; Blank, Sweeney \& Fuller 2014). However it is noted that most sporting teams will have a core of hardened fans who will attend regardless of factors such as team performance, weather conditions and stadium facilities. When spectators return to a stadium repeatedly over time a sense of identification with a venue can be developed (Penny \& Redhead 2009). This love of place has been termed topophilia (Bale 1996; Ramshaw \& Gammon 2010) and home stadiums have been found to generate location pride, awareness, and geographic memories (Ramshaw \& Gammon 2010). Bale $(1996,167)$ suggests that stadium developers and planners have "too often ignored the power of topophilia", including the influence of food and beverage offerings.

In terms of the venue's sportscape, it has been shown that satisfaction is influenced by whether or not spectators feel crowded or cramped, and, therefore, poorly designed seating, with limited elbow room, impact on spectator satisfaction (Lambrecht, Kaefer, and Ramenofsky 2009). Wakefield and Sloan (1995) found that perceived crowding had the strongest effect on spectators' desires to stay or leave a stadium. In addition, where spectators have difficulty reaching important destinations, including the food and beverage outlets, there is evidence of increased spectator frustration and a decreased desire to stay at the venue and to return to future games (Wakefield \& Sloan 1995; Wakefield, Blodgett \& Sloan 1996; Greenwell, Fink \& Pastore 2002; Sarstedt et al. 2014). The helpfulness of employees/volunteers can also impact (both positively and negatively) on spectator satisfaction (Lambrecht, Kaefer, and Ramenofsky 2009). 
Wakefield and Sloan (1995) also identified stadium food prices as an area of dissatisfaction for many sports fans. Spectators with access to hospitality facilities (such complementary refreshments, easier/closer parking, private seating) have been found to be more satisfied with the sportscape than general admission spectators (Lambrecht, Kaefer, and Ramenofsky 2009).

\section{Food choices}

Food plays an important role in the stadium experience (Sukalakamala, Sukalakamala and Young, 2013). Although there is increased awareness of the impact of diet on health, the food offered to spectators at sports stadiums continues to be of poor quality and typically is not healthy (Ireland and Watkins 2010). While there is no one definition of healthy eating options, organisations such as the World Health Organisation (WHO) offer discussions around levels of fat, sugars and cholesterol in foods (WHO 2015). Lee, Heere, and Chung (2013) draw attention to the tendency of sports teams to outsource food and beverage offerings resulting in little or no influence or control over the food and beverage sold in the venues in which they play, and frequently have no healthy eating

policy (Drygas et al. 2013). Stadium food has typically been similar to the high carbohydrate, fat, and calorie offerings found in fast food restaurants (Sukalakamala, Sukalakamala, and Young 2013).

In Major League Baseball (MLB), as far back as the 1990s, there have been a (limited) number of healthy options available at venues, such as frozen yogurt, teriyaki bowls and fresh fruit (Roan 1997). However the more traditional offerings of hot dogs, pretzels, and peanuts have remained dominant. Newer venues such as Icahn Stadium, a multipurpose stadium in New York City that opened in 2005, offer healthier food options including pizzas made on whole-wheat pitas, wraps, grilled sandwiches and low-fat organic parfaits (Fabricant 2005). One MLB club, the San Diego Padres, have even combined in-game physical activity breaks for spectators with healthy and competitively priced foods (Yancey et al. 2009). Choices for food and delivery options have also increased in a number of venues. Yankee Stadium in the New York borough of the Bronx serves Latin food in addition to the obligatory hot dog and hamburger (Fernandez 2007). Miami’s Sun Life Stadium has served multi-cultural menus including Handmade Turkey 
Empanadas, baked potatoes, and a "Pizza Dog" - a foot-long hot dog baked in pizza dough. This variety demonstrates that stadiums across North America seem to be changing by offering greater food diversity including some healthier options.

A number of stadiums, such as Rio Tinto Stadium in Utah, now offer in seat food delivery (PRNewswire 2009). Elsewhere in the United States the San Francisco 49ers have developed a stadium app that shows the length of queues for beverages while the Aviva Stadium in Ireland utilises an app that allows customers to pre-order beverages (IRFU 2014). In Australia the Penrith Panthers are introducing a digital waiter app (Jones 2015) and the Sydney Cricket Ground (SCG) has introduced Q-Hopping technology that allows fans to order and purchase food and beverage using a mobile device (SCG 2014).

Perhaps in response to the limitations of stadium food tailgating, where fans set up portable grills or barbeques in stadium car parks and cook their own food, is a popular North American alternative to in stadium dining. Tailgating has been historically associated with College football in southeastern states of North America (Keaton, Watanabe, \& Gearhart 2015) but its popularity is growing. While the primary motivation for attending a tailgate may be to socialize with friends and family (Drenten et al. 2009), food is an important element (James, Breezeel, \& Ross 2001) and such activities allow fans to choose alternative foods, with tailgating menus now including ribs, steaks and seafood (Russell 2011).

While some North American stadiums have made moves to offer a greater range of good tasting food, many teams and stadiums still need to make greater effort to provide menus that reflect the needs of their fans (Lee, Heere, and Chung 2013). In many European countries sports stadiums are found in less affluent areas that are often surrounded by low-quality housing (Drygas et al. 2013). The spectators that attend these venues may be more familiar and comfortable with less healthy options. In the United Kingdom (UK) Ireland and Watkins (2010) identified that healthy eating is not something that most fans associated with Association football grounds. They found that such fans described the food on offer with terms such as "awful", "abysmal" and "atrocious" and highlighted a lack of both choice and options for those with dietary needs $(2010,684)$. Moreover according to a YouGov report, attendees at UK sports events believe that food is unhealthy (Tobin 2013). In addition to being of poor quality, food in European 
stadiums is also perceived to be overpriced (Miles \& Rines 2004; Sukalakamala, Sukalakamala, \& Young 2013). For example, in their annual survey into the price of attending football matches, the BBC (2015) reveal that a pie can cost up to $£ 4.50$ (AU\$9.13 in January 2016) at some stadiums. However, it has also been found that some fans see "the match is a place for an occasional unhealthy pie [which] means it is unlikely that football fans will take easily to pies being removed from menus" (Ireland \& Watkins 2010, 685).

In Australia meat pies are rather more than an occasional match day food. The meat pie is a traditional food at Australian sporting events and has been equated with the American hotdog (Kovaricek 2010). The meat pie is such traditional fare in Australia that in 2013 one of Australia's iconic venues, the Melbourne Cricket Ground (MCG) alone sold over 300,000 pies (Veenhuyzen 2014). The MCG also sold 600,00 servings of hot chips, 95,000 jam doughnuts, 65,000 burgers and 40,000 pizzas in 2013 (Rolfe 2014). Across Australia stadium menus have been rather predictable with meat pies, hotdogs, chips, and burgers dominating, all of which are typically washed down with beer. As with other countries, Australian venues have been criticised for over-pricing their food and beverage offerings (Tarbert 2015). However studies into Australian fans' perceptions of these offerings are limited.

Sports fans are not homogenous and there are differences in the behaviours and attitudes of fans of different sports (Parry, Jones \& Wann 2014), and so it is important for service providers to understand the wants and needs of their particular fan base to ensure a satisfying experience. In its simplest form, service providers need to understand the different wants and needs of male, female and family spectators. With the nonhomogeneity of sports fans in mind it is important that each sporting code gains an understanding of their fans and their expectations. Furthermore, while a small number of studies have focussed on Australian sports fans (for instance Hill \& Green 2000; Hall, O’Mahony \& Vieceli 2010) the Australian market remains poorly understood. Drawing on data from a survey of sports fans and the researchers' engagement in this field this study aims to bridge these gaps by investigating Australian fans' perceptions of sports stadiums and the food and beverage offerings in these. 


\section{Methodology}

To facilitate comparison to previous research, the methodology adopted in this study was based upon those used in the studies by Wakefield and Sloan (1995) in their study into sport service quality in Japan and America, Wakefield, Blodgett and Sloan's (1996) investigation into spectators' desire to stay at sporting events, Yoshida and James' (2011) and Byon, Zhang and Baker's (2013) examinations of service quality. A concurrent mixed methods, survey based design was primarily utilised.

\section{Participants}

Supporters of the Wallabies team on one of the Australian Rugby Union's membership databases were provided with an email invitation to complete an electronic survey on behalf of the researchers. A total of 293 completed surveys were utilised as part of a pilot study in stadium satisfaction. The majority of those completing the survey were male $(87.7 \%)$ and participants were primarily over the age of 41 , with this category representing $95 \%$ of the sample group (mean $=57.8$, SD 10.0).

The majority of participants $(93.3 \%, n=249)$ were located in the state of New South Wales (NSW), which is on the east coast of Australia. The two NSW-based stadiums featured in the survey were ANZ Stadium (27.1\%) and Allianz Stadium $(51.7 \%)$, both of which are in Sydney. However it was noted that some of these members were prepared to travel interstate to attend games with responses from fans indicating that both Suncorp Stadium in Queensland (17.8\%) and Etihad Stadium in Victoria (3.4\%) were the most recently visited stadium. Of all respondents, over $60 \%$ had attended a game within one month prior to the survey. It was evident that there is a social element to attending a rugby match with $55.9 \%$ of respondents indicating that they attended a match with family, while a further $40.5 \%$ indicated that they attended with friends. Interestingly an overwhelming majority of female respondents (73.0\%) indicated that they attended with family. With sociality playing such an important role it was hypothesised that food would also be important for these fans.

\section{Measures}


The questionnaire contained three sections. The first section asked participants to provide basic demographic information regarding gender, age, postcode and details on their most recent visit to a sports stadium. In the second section participants indicated their agreement with a series of statements based on their feelings towards the stadium they had identified. The survey utilised eight scales; getting to and around the stadium; stadium aesthetics; entertainment; screens and scoreboards; seating; food and beverage; stadium atmosphere; and stadium management - the survey scales can be found in appendix 1 .

To enhance the reliability and validity of the research tool existing scales (that had previously been tested) were used, or adapted, for the purpose of this study. Additional questions relating to the design of the stadium and topophilia were added to scales previously utilised by Wakefield and Sloan (1995), Wakefield, Blodgett and Sloan (1996), Yoshida and James (2011) and Byon, Zhang and Baker (2013). Additional questions were added following discussions with a leading sport architect and based on the researchers' knowledge and observations of sports fans. The survey was then piloted with a small sample to test the face validity of the new research tool. The questionnaire was found to work well and needed few changes.

Participants were provided with multiple Likert-type scale items, with five point response options, for each scale ranging from $1=$ not at all to $5=$ very much. A single pre-existing scale could not be found that covered all aspects of the sporting experience and so a new scale was developed for this study. Mean scores were calculated for each individual scale item and, to allow comparisons across scales, for each scale. Given that a five-point Likert-type system was used, a mean score of greater than 2.50 was taken to indicate that respondents were satisfied with a particular scale or item.

The final section provided respondents with the chance to provide their thoughts of the most positive and most negative aspects of the stadium via two open-ended questions: What aspects of the stadium do you consider to be particularly positive? and What aspects of the stadium do you consider to be particularly negative? Answers to these two questions were collated and then initially displayed via a word cloud, before being thematically analysed. Word clouds present the most commonly used words arranged with the size of the word corresponding to the frequency of its occurrence in 
responses. Such a visual trend analysis approach has been dubbed as a "simple yet effective approach" (Hunt, Gao \& Xue 2014, 851) that is able to provide instant insight into responses. Such an approach has been used previously in a variety of studies such as those by Ahearn (2014), Hunt, Gao and Xue (2014), and Guggenheim et al. (2015).

\section{Findings and discussion}

As shown in Table 1 participants were most satisfied with Seating and Stadium Management and least satisfied with Entertainment and Food and Beverage offerings. The scores for the Food and Beverage scale (1.89) and the Entertainment scale (1.79) were considerably lower than other scales, and this indicates dissatisfaction with these elements. However, it should be noted that the ARU members are likely to have personal and emotional connections to the Wallabies. Therefore, such traditional spectators are likely to be less consumption focussed, with entertainment and other commodificationdriven features of sport having less influence over them (Giulianotti 2002). The low score for the Food and Beverage scale was therefore identified as being the greatest point of dissatisfaction for participants and required further investigation.

INSERT TABLE 1 HERE

Food and Beverage was the second-lowest ranked scale and no single scale items received a mean rating higher than 2.16 out of 5 , with the price of food rated the lowest (mean $=1.66)$. Of the stadiums included within the survey, ANZ Stadium was rated the poorest in seven of the nine scale items. Etihad Stadium proved to be the 'best' performer for Food and Beverage with an overall mean rating of 2.28.

\section{INSERT TABLE 2 HERE}

Through an analysis of qualitative responses it was evident that participants enjoyed those stadiums that were in close proximity to city centres, as the availability of restaurants and bars allowed them to socialise before and after the game with friends. In terms of food and beverage offerings positive attitudes only otherwise referred to the 
convenience of within-stadium outlets. However, in response to the question What aspects of the stadium do you consider to be particularly negative? there were numerous food and beverage-related responses and the word cloud below (see figure 1) clearly shows food and beverage provision as a particular point of dissatisfaction.

\section{INSERT FIGURE 1 HERE}

Responses to this question indicated that there is a need for a greater variety of food options at stadiums. Some participants were looking for options that present healthier alternatives to traditional fast foods and they are also looking for increased quality in what they can buy. Comments indicated that the poor food quality and the lack of healthy options meant that some participants did not eat at stadiums:

No healthy food options - I do not eat at the ground because of this.

Terrible food choices (no fresh/healthy food at all) \& exorbitant prices.

However comments relating to the food and beverage options available, and in particular to healthy options, were far less common than comments on the price and time taken to be served. Terms such as "extreme" and "exorbitant" were used to describe the prices of food and beverage at venues. In addition to the price of food and beverages respondents also indicated that there was a limited number of ways in which to order and receive food. This limited number of delivery options then results in difficulties around queuing for food and beverage that further impacts on the fan experience. The standard of service was a common theme with a number of respondents suggesting that inexperienced staff contributed towards poor levels of service quality. The frustration with the food and beverage options appears to be long-standing and was exemplified in the following comment:

Catering has always been an issue, many surveys over the years with limited change. 
The high price of food in Australian stadiums has been criticised by fans and the media alike and it is perhaps unsurprising that this should also be the case in this study. Australian fans want affordable or 'value for money' food that is served quickly, and increasingly without the need to queue. As was found to be the case with European fans it is worrying that these considerations are believed to be more significant than healthy food options (Miles \& Rines 2004; Ireland \& Watkins 2010; Sukalakamala, Sukalakamala, \& Young 2013). While in the UK having a pie at a sports match is seen as being a guilty pleasure (Ireland \& Watkins 2010) this is not the case in Australia as pies are much more popular in the wider society. In Australia the tradition of eating pies (and similar foods) may therefore be hard to move away from. Although this may be more evident for Australian males rather than females where there is some evidence to support Australian male's preference for both fast food and meat options (Savige, Ball, Worsley, Crawford 2007).

\section{Recent developments}

Recent Australian stadium redevelopments may suggest that the tradition of poor food and beverage offering is changing. The Adelaide Oval and SCG Northern Stand redevelopments have included better quality food options, which spectators appear to have embraced. Between 2008 and 2014 the Adelaide Oval was redeveloped to include a new mid-price corporate product called the Stadium Club. The food offered at the Stadium Club included the 'Hill of Grace Restaurant', an à la carte restaurant specialising in local seasonal food and local beverages.

\section{INSERT FIGURE 2 HERE}

As mentioned in an email to the research team from Adam Hannon, September 23, 2015 the stadium operator took a "leap of faith" initially in developing the Stadium Club, as nothing similar had been offered at a stadium in South Australia. It has proven to be popular as Stadium Club memberships reached 96\% capacity for the 2014/15 and 2015/16 seasons, memberships were at $100 \%$ capacity (with a waiting list) for the 
upcoming 2016/17 season and event day attendances totalled 40,265 from March 2014 March 2015.

The 2012-2014 SCG Northern Stand redevelopment included a 'food court' style food area and a microbrewery bar area offering higher quality and healthier food options, such as Doyles brand seafood and Noodle Shack brand Asian food, and higher quality custom beers. These healthier and higher quality food and beverage options constitute 11 of the 31 food and beverage counters in the redeveloped stand.

\section{INSERT FIGURES 3 AND 4 HERE}

As with the Adelaide Oval example, the food and beverage offering in the new SCG redevelopment has also been very popular with spectators. In a conversation with the researchers SCG Trustee Stuart MacGill, January 23, 2015 revealed that food and beverage sales for the opening 2015 cricket Test match surpassed the equivalent 2012 sales by $40 \%$, exceeding SCG Trust estimates by $30 \%$. Interestingly, the new SCG food court-still offers burgers, pizzas and pies (albeit made-to-order burgers and pizzas and high quality gourmet meat pies). The popularity of the food at the new food court area may have as much to do with food quality as it does with being a healthy option but gourmet products may be expected to contain higher quality ingredients and should, therefore, be healthier. Despite the range of perceived healthier options there is still only a limited vegetarian offering available with a small number of outlets; providing an inadequate range of vegetarian meals. The food court and associated outdoor dining area are also open for major events held at other venues within the SCG precinct, expanding and enhancing the food and beverage offerings at adjacent grounds and improving the pre and post-match spectator experience.

Both of these examples would suggest Australian spectators are willingly to move away from low quality unhealthy food options if given a reasonable alternative. However, as was found in Lee, Heere, and Chung's (2013) study stadium operators in Australia commonly outsource the operation of food and beverage outlets to external contractors. By relinquishing control over these offerings Australian stadiums do not have direct 
control over the choices provided to spectators and cannot ensure that healthy options are provided. In addition external contractors typically operate a business model where costs are minimised and may prefer to offer cheap to produce food and beverages, again typified by pies, with larger returns than more expensive or more time intensive alternatives. As sporting organisations seek to increase the stadium attendance there may be a case for a revised business model which is driven by the need to provide a range of quality, healthy food options to meet the needs of fans of all ages, as opposed to a business model which pushes quality down in order to maximise profits.

\section{The future for stadium food in Australia}

Food and beverage offerings were found to be a point of frustration for fans of the Wallabies. From an analysis of qualitative answers this frustration was due to a combination of the price, the ordering and delivery options, and the perceived poor service quality. In particular, food and beverage prices were seen to being too high for the quality and variety of food on offer. While the Etihad Stadium and the MCG in Melbourne have recently dropped food prices (Rolfe 2015) these are still higher than those at sporting events elsewhere. For instance the Augusta National Golf Course, home to the US Masters maintains much lower prices with the highest priced food item only US\$3 (AU\$4.28 in January 2016) and the most expensive beverage is US\$5 (AU\$7.14) for an imported beer (News Limited 2015). The variety of food available in North American venues is also certainly not seen in Australian stadiums and Australian sports fans are not unaware of such global comparisons and are unhappy with being asked to pay AU\$5 for a bottle of water or AU\$5 for a pie of poor quality (Cherny 2015).

Australia lags behind other nations in terms of food and beverage offerings in its stadiums and the data from this study reveals the levels of dissatisfaction felt by Australian spectators with the traditional offerings. Our observations of recent stadium redevelopments reveal that Australian spectators have embraced changes in stadium food and beverages, as shown by membership and sales figures for the Adelaide Oval and the SCG redevelopments respectively. The onus is now on other Australian stadiums who are yet to improved their food and beverage offerings to follow the example of the Adelaide Oval, the SCG and their North American counterparts to provide more varied, higher 
quality, healthier food and beverage options that represent better value for money. Australian spectators are likely to always eat all the pies but are now demanding these are high quality, healthy and value for money.

\section{Recommendations}

For stadium food options (outside of corporate à la carte offerings) to be considered realistic alternatives to the current pies, chips and pizzas we would recommend a number of principles be followed. Any alternate would need to be:

- At a similar or better price than current offerings;

- Quick to order/be served;

- Easy to eat (ideally with one hand);

- Portion controlled meals factoring in nutritional requirements;

- An existing popular food choice in the city the stadium is located.

One suitable alternative, which seemingly follows all of these principles, is the Australian version of the Japanese Nori or sushi roll. Sushi rolls are increasingly popular in Australian shopping mall food courts (Langley 2015), they are quick and easy to order and serve (they are almost always pre-prepared), they can be eaten with one hand, are generally healthy (although this depends on filling) and at AU\$3-\$3.50 each they are cheaper than pies and burgers. One added benefit of such an offering is that non-meat fillings are common and they would provide a good option for those spectators who do not eat meat. Further research investigating female and family food preferences would benefit stadium food service providers particularly if this has been one of the barriers to attending live sport venues as reflected in low attendance figures for females.

We also recommend that future research explore the offerings found in the food courts of large shopping malls (such as Westfield shopping centres in Australia - see Figure 5). These food courts have infrastructure and patronage similarities to Australian stadiums and yet provide multiple and varied, high quality options to customers. The SCG Northern Stand redevelopment has shown the food court layout can physically work in the stadium environment and further research should explore the feasibility and benefits of including such options in stadiums. 


\section{INSERT FIGURE 5 HERE}

While these recommendations offer the potential to draw larger crowds from more diverse population groups to stadiums, there will be a minimal impact unless such changes are well marketed and communicated. This marketing also needs to take place within stadiums so that options that are healthier and family orientated are easily identified and accessible. This information should include the nutritional value of food and beverage offerings. While food may often be the focus of healthy eating, it is also important to offer healthier alternatives to beverages such as soft drinks, which contain high sugar contents. Finally, given the overrepresentation of male participants in our survey $-87.7 \%$ compared to $63.6 \%$ of spectators at rugby union in Australia generally (ABS 2012) - additional research is needed to examine the food and beverage preferences of female spectators.

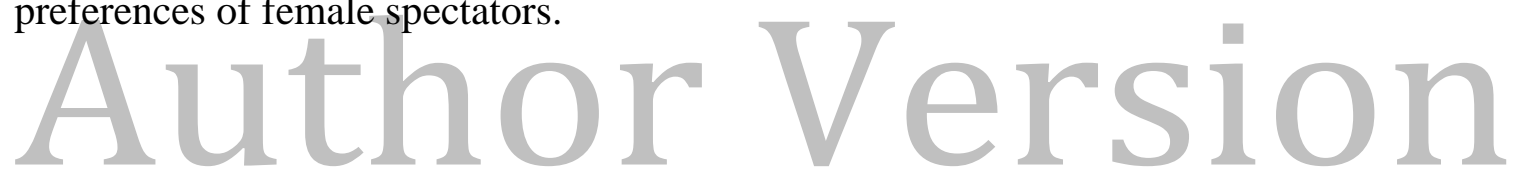


Table 1. Scale mean scores

\begin{tabular}{|l|c|}
\hline Scale & Mean Score \\
\hline Seating & 3.77 \\
\hline Stadium Management & 3.17 \\
\hline Getting to and Around the Stadium & 3.16 \\
\hline At the Stadium (Topophilia) & 2.98 \\
\hline Screens and Scoreboards & 2.87 \\
\hline Aesthetics & 2.79 \\
\hline Food and Beverage & 1.89 \\
\hline Entertainment & 1.79 \\
\hline
\end{tabular}

Author Version 
Table 2. Food and Beverage Scale Item mean scores

\begin{tabular}{|c|c|c|c|c|c|}
\hline \multicolumn{6}{|l|}{ Food \& Beverage } \\
\hline & \begin{tabular}{|l} 
All \\
Stadiums
\end{tabular} & ANZ & Allianz & Etihad & Suncorp \\
\hline This stadium offers a wide variety of food choices & 2.16 & 2.21 & 2.09 & 2.20 & 2.17 \\
\hline $\begin{array}{l}\text { This stadium offers a wide variety of beverages } \\
\text { choices }\end{array}$ & 2.14 & 1.94 & 2.13 & 2.67 & 2.29 \\
\hline This stadium offers good tasting food & 2.03 & 1.97 & 2.03 & 2.00 & 2.02 \\
\hline This stadium offers fast service for beverages & 1.98 & 1.75 & 1.86 & 2.17 & 2.55 \\
\hline This stadium offers healthy food options & 1.83 & 1.76 & 1.83 & 1.60 & 1.86 \\
\hline $\begin{array}{l}\text { This stadium offers a variety of ways to order and } \\
\text { receive your food }\end{array}$ & 1.76 & 1.66 & 1.71 & 2.60 & 1.88 \\
\hline $\begin{array}{l}\text { This stadium offers a variety of ways to order and } \\
\text { receive your beverages }\end{array}$ & 1.75 & 1.55 & 1.68 & 2.40 & 2.05 \\
\hline This stadium offers reasonably priced beverages & 1.70 & 1.43 & 1.72 & 2.67 & 1.81 \\
\hline This stadium offers reasonably priced food & 1.66 & 1.43 & 1.64 & 2.20 & 1.90 \\
\hline Overall & 1.89 & 1.74 & 1.85 & 2.28 & 2.06 \\
\hline
\end{tabular}


Figure 1. Word Cloud of responses to the questions What aspects of the stadium do you consider to be particularly negative?
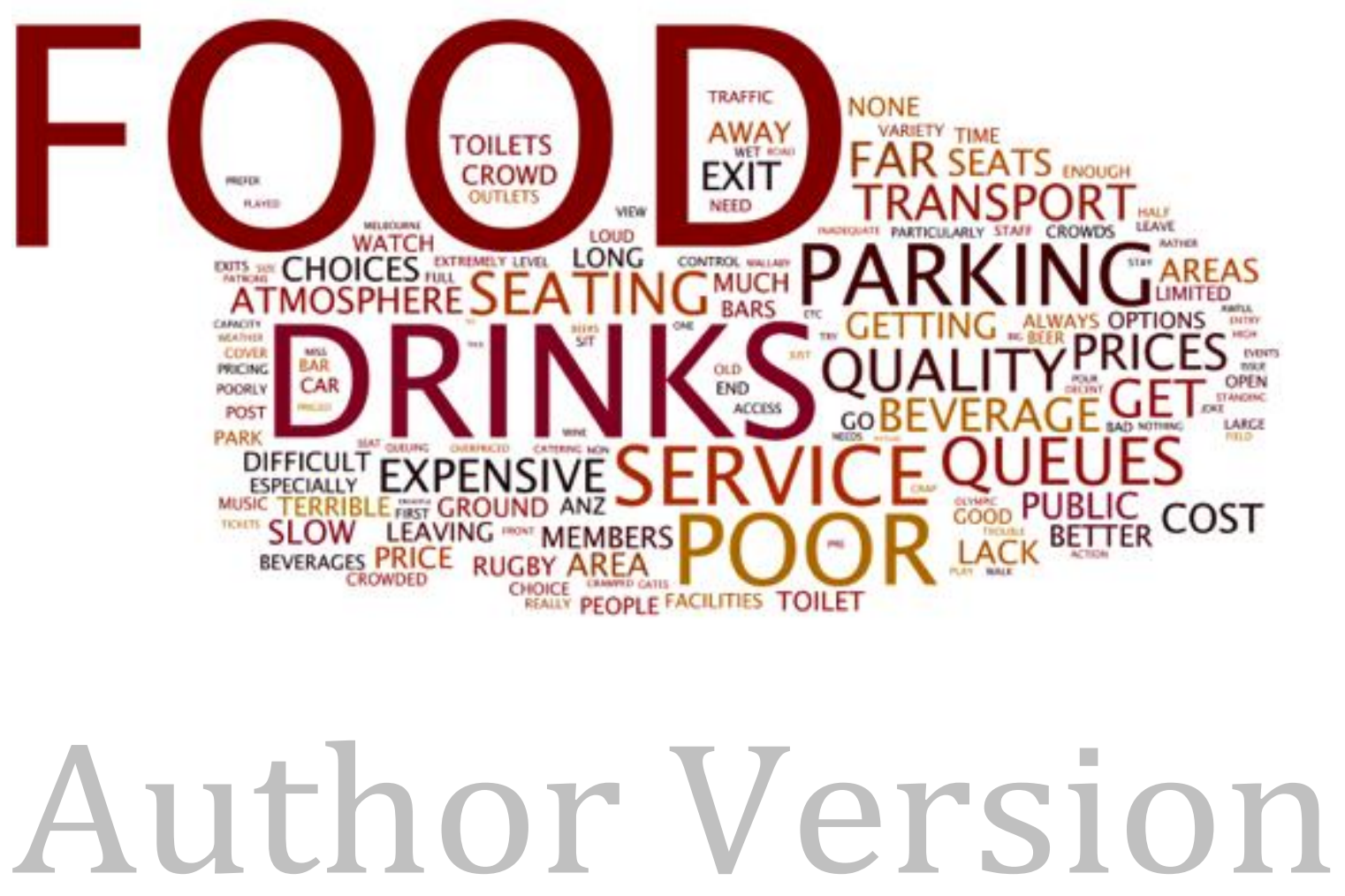
Figure 2. The Stadium Club at the Adelaide Oval

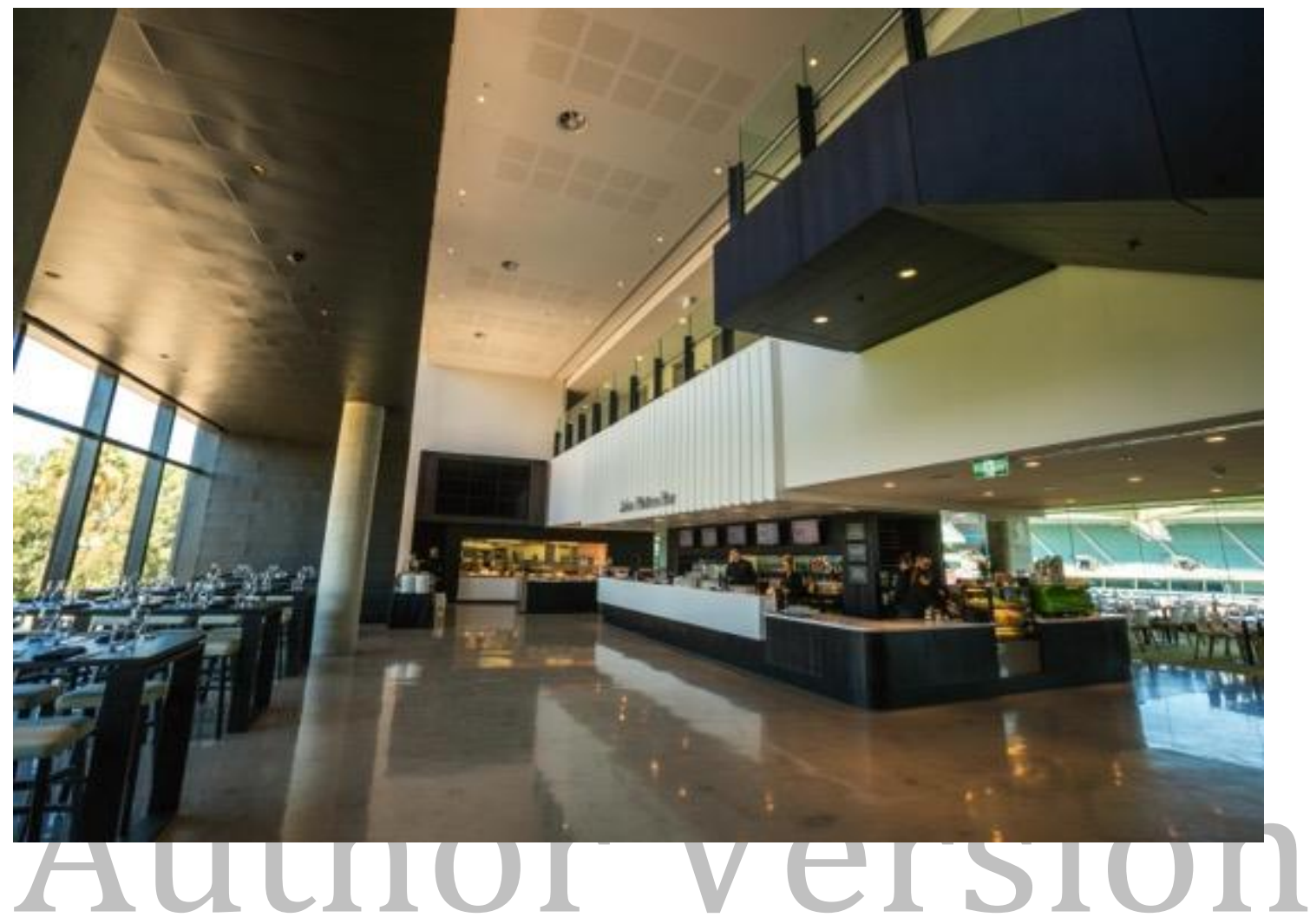


Figure 3. 'Food court' style food area in SCG Northern Stand

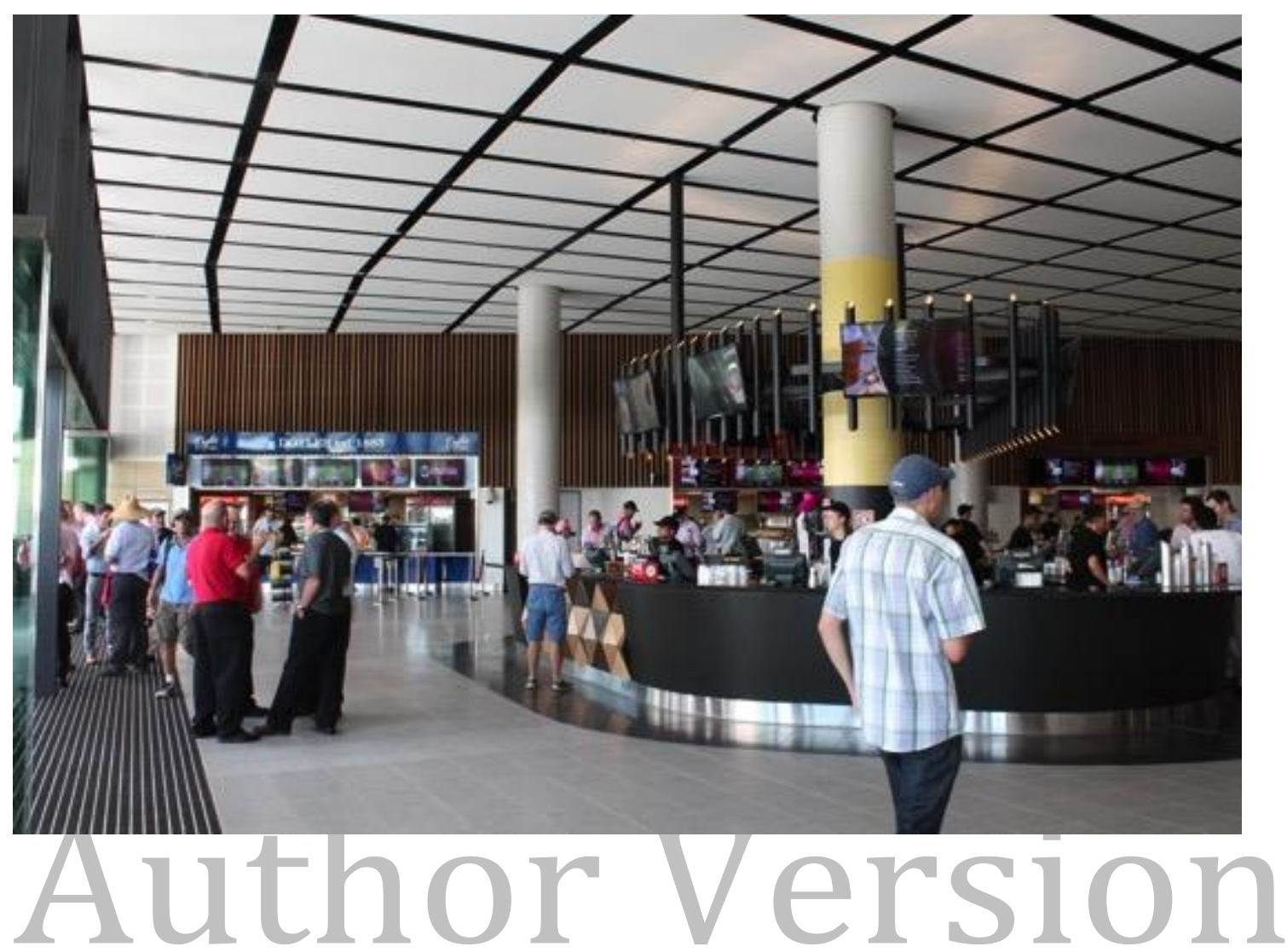


Figure 4. Microbrewery in SCG Northern Stand

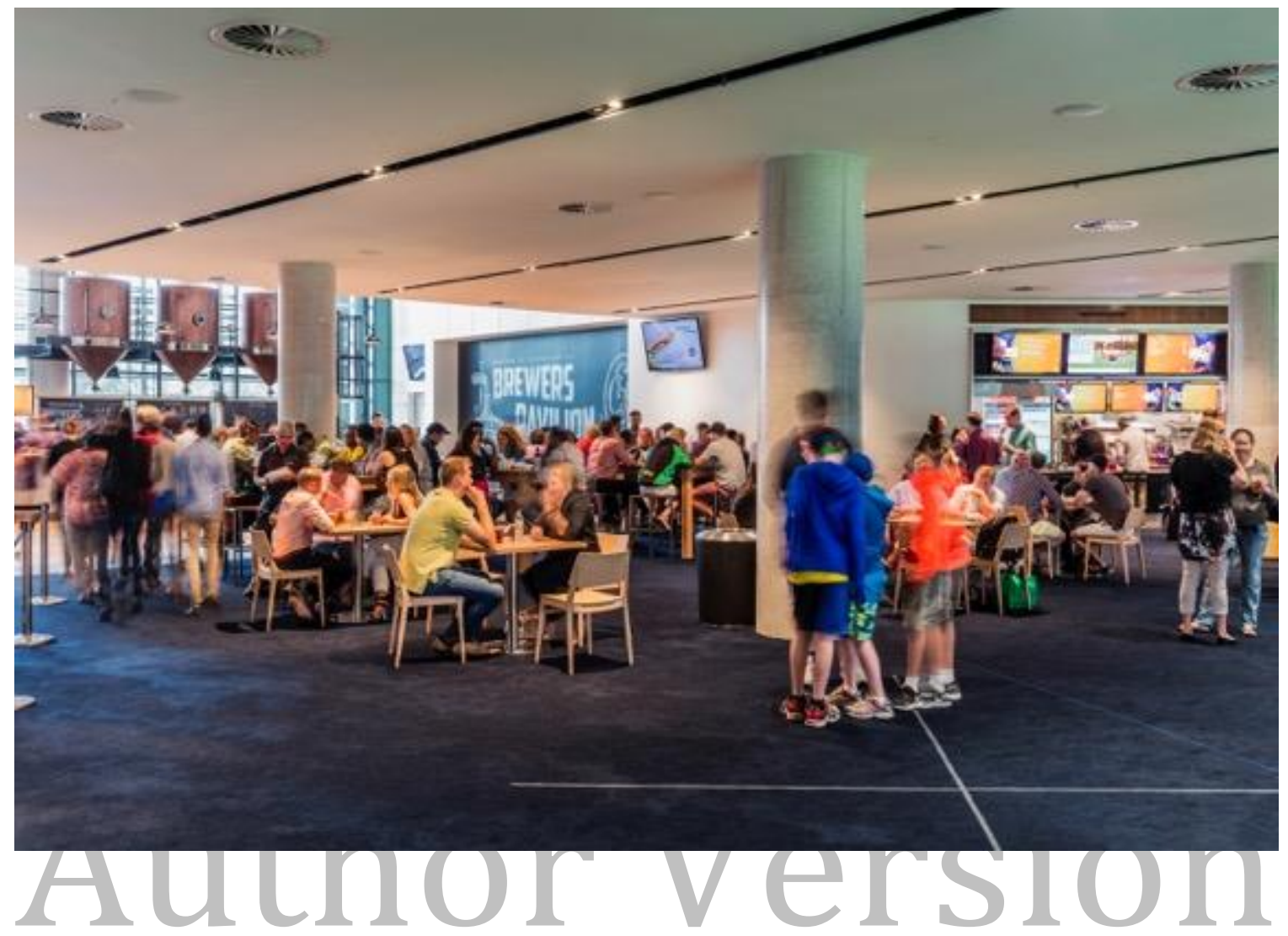


Figure 5. Food court at Westfield Miranda, Sydney

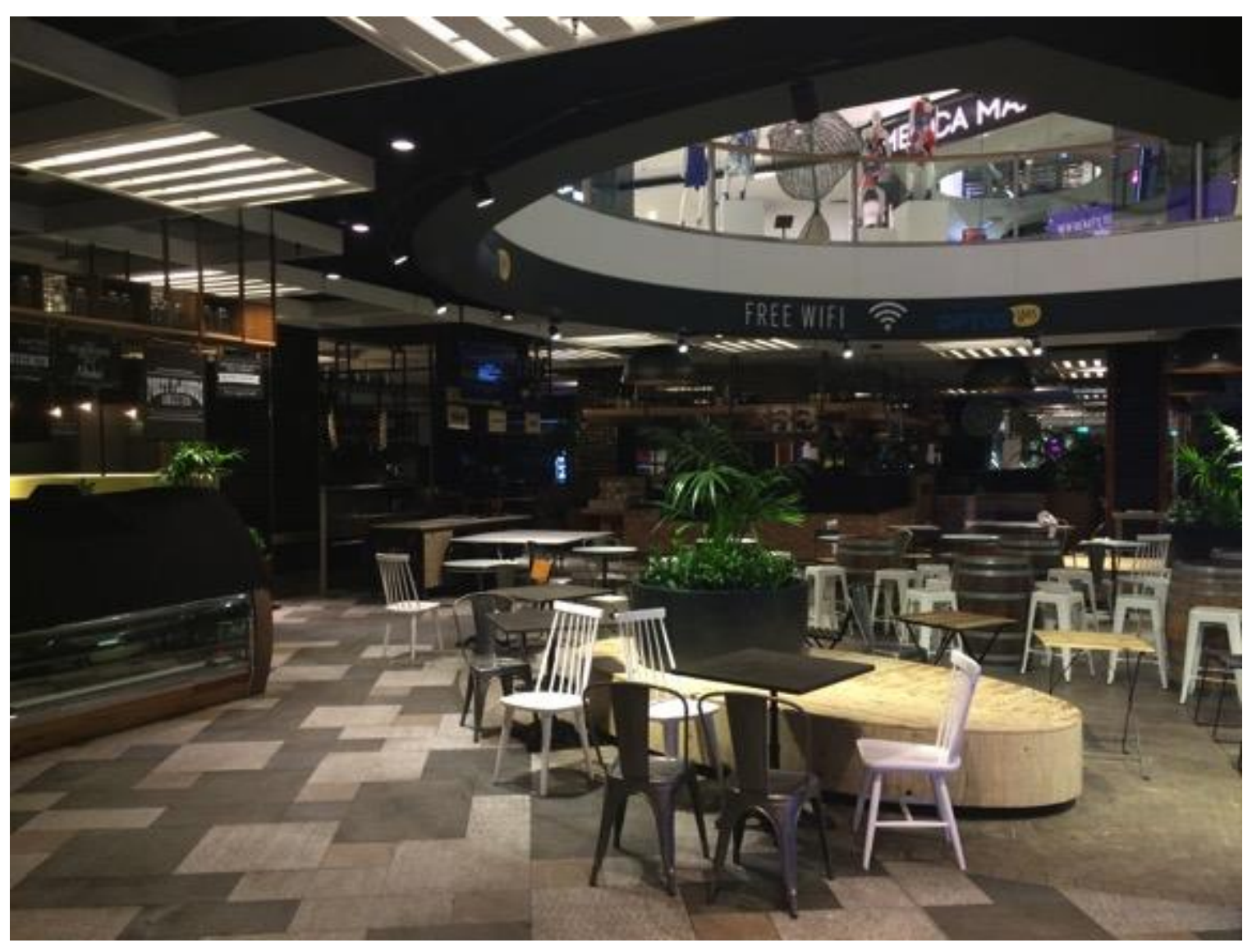




\section{Appendix 1. Full Survey Scales}

\begin{tabular}{|c|}
\hline $\begin{array}{r}\text { Getting to and Around the stadium } \\
\end{array}$ \\
\hline The stadium is well served by public transport \\
\hline Local roads make it easy to get to this stadium \\
\hline This stadium has ample parking \\
\hline Stadium parking is easy to get out of after the game \\
\hline Stadium parking is conveniently located \\
\hline Signs at this stadium help you know where you are going \\
\hline Signs at this stadium give clear directions of where things are located \\
\hline The stadium layout makes it easy to get to your seat \\
\hline $\begin{array}{l}\text { The stadium layout makes it easy to get to the restrooms or food and } \\
\text { beverage outlets }\end{array}$ \\
\hline Stadium Aesthetics \\
\hline This stadium is painted in attractive colours \\
\hline This stadium's architecture gives it an attractive character \\
\hline This is an attractive stadium \\
\hline This stadium is well maintained \\
\hline This stadium is modern \\
\hline There is plenty of legroom in the seating area \\
\hline There is plenty of elbowroom in this seating area \\
\hline This stadium provides comfortable seats $r(T)$ \\
\hline The arrangement of seats provides plenty of space \\
\hline ( Entertainment $(1)$ \\
\hline Pregame shows/entertainment added to your experience at this stadium \\
\hline $\begin{array}{l}\text { Interval/halftime shows/entertainment added to your experience at this } \\
\text { stadium }\end{array}$ \\
\hline Postgame shows/entertainment added to your experience at this stadium \\
\hline During game shows/entertainment added to your experience at this stadium \\
\hline $\begin{array}{l}\text { Shows/entertainment at this stadium provide a suitable degree of } \\
\text { interactivity }\end{array}$ \\
\hline Screens and Scoreboards \\
\hline The screens/scoreboards are entertaining to watch \\
\hline The screens/scoreboards add excitement to the game \\
\hline This stadium provides interesting statistics/information \\
\hline This stadium has high quality screens/scoreboards \\
\hline The screens/scoreboards are conveniently located \\
\hline You rely on the screens/scoreboards to watch the game \\
\hline Seating \\
\hline The whole playing area is easily visible from your preferred seating location \\
\hline Your view is not obstructed from your preferred seating location \\
\hline $\begin{array}{l}\text { When the ball is in the air your view of it is not obscured from your } \\
\text { preferred seating location }\end{array}$ \\
\hline You are protected from the elements in your preferred seating location \\
\hline Your preferred seating location is close enough to the playing field \\
\hline
\end{tabular}




\begin{tabular}{|l|}
\hline \multicolumn{1}{|c|}{ The sound quality is good in your preferred seating location } \\
\hline \multicolumn{1}{|c|}{ Atium (Topophilia) } \\
\hline You enjoy spending time at this stadium \\
\hline You like to stay at this stadium for as long as possible \\
\hline You like to stay for the whole game \\
\hline $\begin{array}{l}\text { You are able to access the internet via your mobile phone or other devices at } \\
\text { this stadium }\end{array}$ \\
\hline You have a good phone signal at this stadium \\
\hline $\begin{array}{l}\text { You are able to access social media sites such as Twitter and Facebook at } \\
\text { This stadium }\end{array}$ \\
\hline You feel at home at this stadium \\
\hline The journey to this stadium has special meaning for you \\
\hline You know your way around this stadium \\
\hline \\
\hline This stadium offers a wide variety of food choices \\
\hline This stadium offers good tasting food \\
\hline This stadium offers healthy food options \\
\hline This stadium offers reasonably priced food \\
\hline This stadium offers a variety of ways to order and receive your food \\
\hline This stadium offers a wide variety of drinks choices \\
\hline This stadium offers reasonably priced drinks \\
\hline This stadium offers fast service for drinks \\
\hline This stadium offers a variety of ways to order and receive your drinks \\
\hline Stadium Management \\
\hline This stadium maintains clean restrooms \\
\hline This stadium maintains clean food and beverage areas \\
\hline This stadium maintains clear walkways and exits \\
\hline This stadium makes certain that offensive fans are controlled \\
\hline This stadium monitors abusive fans \\
\hline This stadium is concerned about controlling abusive fans \\
\hline Queues for toilets at this stadium are acceptable \\
\hline Queues for food and drinks at this stadium are acceptable \\
\hline It is easy to enter this stadium \\
\hline It is easy to leave this stadium \\
\hline
\end{tabular}




\section{References}

ABS. 2012. Sport and Recreation: A Statistical Overview. edited by ABS: Australian Bureau of Statistics.

Ahearn, Laura M. 2014. "Detecting research patterns and paratextual features in AE word clouds, keywords, and titles." American Ethnologist 41 (1): 17-30. doi: 10.1111/amet.12056.

Anagnostopoulos, Christos. "From Corporate Social Responsibility (CSR) to... Club Stakeholder Relationship (CSR): the case of football." The Social Responsibility Research Network Constitution (2011).

Bale, John. 1996. "Space, Place and Body Culture: Yi-Fu Tuan and a Geography of Sport." Geografiska Annaler. Series B, Human Geography 78 (3): 163-171. doi: $10.2307 / 490831$.

Barrett, Chris. 2016. "Big Bash League jumps into top 10 of most attended sports leagues in the world." Last Modified January 11th 2016 Accessed 20th January. http://www.smh.com.au/sport/cricket/big-bash-league-jumps-into-top-10-of-mostattended-sports-leagues-in-the-world-20160110-gm2w8z.html.

BBC. 2015. "Price of Football: Most ticket prices frozen or reduced." Last Modified 14th October 2015 Accessed 15th October. http://www.bbc.com/sport/0/football/34531731.

Blank, Ashley, Kristi Sweeney, and Rhema Fuller. 2014. "Room for Growth in Professional Sport: An Examination of the Factors Affecting African-American Attendance." Sport Marketing Quarterly 23 (4): 225-240.

Bouchet, Patrick, Guillaume Bodet, Iouri Bernache-Assollant, and Faycel Kada. 2011. "Segmenting sport spectators: Construction and preliminary validation of the Sporting Event Experience Search (SEES) scale." Sport Management Review 14 (1): 42-53.

Byon, Kevin K., James J. Zhang, and Thomas A. Baker. 2013. "Impact of core and peripheral service quality on consumption behavior of professional team sport spectators as mediated by perceived value." European Sport Management Quarterly 13 (2): 232-263.

Cherny, Daniel. 2015. "Etihad Stadium under pressure after MCG lowers food and drink prices." The Age, Last Modified March 3rd 2015 Accessed 1oth August. http://www.theage.com.au/afl/afl-news/etihad-stadium-under-pressure-after-mcglowers-food-and-drink-prices-20150302-13sga0.html.

Drenten, Jenna, Cara Okieshen Peters, Thomas Leigh, and Candice R. Hollenbeck. 2009. "Not Just a Party in the Parking Lot: An Exploratory Investigation of the Motives Underlying the Ritual Commitment of Football Tailgaters." Sport Marketing Quarterly 18 (2): 92-106.

Drygas, Wojciech, Joanna Ruszkowska, Matthew Philpott, Olav BjÖrkstrÖm, Mike Parker, Robin Ireland, Federico Roncarolo, and Maria Tenconi. 2013. "Good practices and health policy analysis in European sports stadia: results from the 'Healthy Stadia' project." Health Promotion International 28 (2): 157-165. doi: 10.1093/heapro/dar088. 
Fabricant, Florence. 2005. "Healthier Food Lineup at New Stadium." New York Times, 27th April 2005, 10. http://www.nytimes.com/2005/04/27/style/dining/food-stuffhealthier-food-lineup-at-new-stadium.html.

Fernandez, Manny. 2007. "Latin Food at Yankee Stadium. Now, How About That!" New York Times, 11th May 2007. http://www.nytimes.com/2007/05/11/nyregion/11food.html?_r=0.

Giulianotti, Richard. 2002. "Supporters, Followers, Fans, and Flaneurs." Journal of Sport \& Social Issues 26 (1): 25-46. doi: 10.1177/0193723502261003.

Greenwell, T. Christopher, Janet S. Fink, and Donna L. Pastore. 2002. "Assessing the Influence of the Physical Sports Facility on Customer Satisfaction within the Context of the Service Experience." Sport Management Review 5 (2):129-148. doi: http://dx.doi.org/10.1016/S1441-3523(02)70064-8.

Guggenheim, Lauren, S. Mo Jang, Soo Young Bae, and W. Russell Neuman. 2015. "The Dynamics of Issue Frame Competition in Traditional and Social Media." The ANNALS of the American Academy of Political and Social Science 659 (1): 207224. doi: 10.1177/0002716215570549.

Hall, John, Barry O'Mahony, and Julian Vieceli. 2010. "An empirical model of attendance factors at major sporting events." International Journal of Hospitality Management 29 (2): 328-334.

Hill, Brad, and B. Christine Green. 2000. "Repeat Attendance as a Function of Involvement, Loyalty, and the Sportscape Across Three Football Contexts." Sport Management Review 3 (2):145-162. doi: http://dx.doi.org/10.1016/S14413523(00)70083-0.

Hunt, Carter A., Jie Gao, and Lan Xue. 2014. "A visual analysis of trends in the titles and keywords of top-ranked tourism journals." Current Issues in Tourism 17 (10):849-855. doi: 10.1080/13683500.2014.900000.

Inoue, Yuhei, Sami Yli-Piipari, Todd Layne, Heather O. Chambliss, and Carol C. Irwin. 2015. "A preliminary study of a professional sport organization's family-centered health promotion initiative." International Review on Public and Nonprofit Marketing 12 (2): 189-205.

Ireland, Robin, and Francine Watkins. 2010. "Football fans and food: a case study of a football club in the English Premier League." Public Health Nutrition 13 (05):682-687. doi: doi:10.1017/S1368980009991765.

IRFU. 2014. "Beat The Queue At Aviva Stadium With 'My Order App'." Last Modified March 26th 2014 Accessed 19th April. http://www.irishrugby.ie/news/30247.php - .VbYQJWDoYWl.

James, Jeffrey, G. Steven Breezeel, and Stephen Ross. 2001. "A Two-Stage Study of the Reasons to Begin and Continue Tailgating." Sport Marketing Quarterly 10 (4):212.

Jones, Grant. 2015. "New app will allow football lovers to have food ordered and delivered to their stadium seats." Last Modified February 25th 2015 Accessed 19th April. http://www.dailytelegraph.com.au/lifestyle/food/new-app-will-allowfootball-lovers-to-have-food-ordered-and-delivered-to-their-stadium-seats/storyfnov1g0j-1227238025816.

Keaton, Shaughan A., Nicholas M. Watanabe, and Christopher C. Gearhart. 2015. "A Comparison of College Football and NASCAR Consumer Profiles: Identity 
Formation and Spectatorship Motivation." Sport Marketing Quarterly 24 (1): 4355.

Kovaricek, Elk. 2010. "The glorious meat pie and humble pie floater." ABC Adelaide, Last Modified 31st May 2010 Accessed 20th July. http://blogs.abc.net.au/sa/2010/05/the-glorious-meat-pie-and-humble-piefloater.html? site=adelaide\&program=adelaide_afternoons.

Lambrecht, Keith W., Frederick Kaefer, and Samuel D. Ramenofsky. 2009. "Sportscape Factors Influencing Spectator Attendance and Satisfaction at a Professional Golf Association Tournament." Sport Marketing Quarterly 18 (3): 165-172.

Langley, Sophie. 2015. "Australia: land of the rising sushi (and the falling spring roll)." Aus Food News, Last Modified January 19th 2015 Accessed 27th September. http://ausfoodnews.com.au/2015/01/19/australia-land-of-the-rising-sushi-and-thefalling-spring-roll.html.

Lee, Seunghwan, Bob Heere, and Kyu-soo Chung. 2013. "Which Senses Matter More? The Impact of Our Senses on Team Identity and Team Loyalty." Sport Marketing Quarterly 22 (4): 203-213.

Lera-López, Fernando, Andrea Ollo-López, and Manuel Rapún-Gárate. 2012. "Sports spectatorship in Spain: attendance and consumption." European Sport Management Quarterly 12 (3): 265-289. doi: 10.1080/16184742.2012.680897. Madrigal, Robert. 2006. "Measuring the Multidimensional Nature of Sporting Event Performance Consumption." Joournal of Leisure Research 38 (3): 267-276.

Miles, Louella, and Simon Rines. 2004. Football Sponsorship \& Commerce: An Analysis of Sponsorship and Commercial Opportunities in Football. Buckfastleigh, UK: International Marketing Reports Ltd.

News Limited. 2015. "Masters food prices are ridiculous." Last Modified April 9th 2015 Accessed 9th April. http://www.news.com.au/sport/sports-life/masters-foodprices-are-ridiculous/story-fno61i58-1227296602993.

Parnell, Daniel, Andy Pringle, Jim McKenna, Stephen Zwolinsky, Zoe Rutherford, Jackie Hargreaves, Lizzie Trotter, Michael Rigby, and David Richardson. 2015

"Reaching older people with PA delivered in football clubs: the reach, adoption and implementation characteristics of the Extra Time Programme." BMC Public Health 15 (1): 220.

Parry, Keith D, Ian Jones, and Daniel L. Wann. 2014. "An Examination of Sport Fandom in the United Kingdom: A Comparative Analysis of Fan Behaviors, Socialization Processes, and Team Identification." Journal of Sport Behavior 37 (3): 251-267.

Penny, Simon, and Steve Redhead. 2009. "We're not really here: Manchester City, mobility and placelessness." Sport in Society 12 (6): 755-764. doi: 10.1080/17430430902944217.

PRNewswire. 2009. "In-Seat Food Delivery Available Stadium-Wide at Rio Tinto." PR Newswire, 23rd July 2009. http://www.prnewswire.com/news-releases/in-seatfood-delivery-available-stadium-wide-at-rio-tinto-62265612.html.

Ramshaw, Gregory, and Sean Gammon. 2010. "On home ground? Twickenham Stadium Tours and the construction of sport heritage." Journal of Heritage Tourism 5 (2): 87-102. doi: 10.1080/17438730903484184. 
Roan, Shari. 1997. "Buy Me Some Peanuts and Yogurt?; Food: Survey finds healthy choices have become available at all major league stadiums." Los Angeles Times, 11th June1997, 3-C, 3:4.

Rowe, David, and Jay Scherer. 2014. Sport, public broadcasting, and cultural citizenship: signal lost? New York: Routledge.

Rolfe, Peter. 2014. "Price rises for food and drink at MCG and Etihad Stadium hit footy fans." Herald Sun, Last Modified March 15th 2014 Accessed 10th August. http://www.heraldsun.com.au/news/victoria/price-rises-for-food-and-drink-atmcg-and-etihad-stadium-hit-footy-fans/story-fniOfit3-1226855806466.

Rolfe, Peter. 2015. "Etihad Stadium lowers food prices ahead of 2015 AFL season, following MCG." Last Modified March 26th 2015 Accessed 20th July.

http://www.heraldsun.com.au/sport/afl/etihad-stadium-lowers-food-prices-aheadof-2015-afl-season-following-mcg/story-fni5ezdm-1227279029679.

Russell, Natalie Ermann. 2011. "Forget stadium food -- just eat up at the tailgate." USA TODAY, 21st September 2011. http://www.dailycomet.com/article/20110921/WIRE/110929934.

SCG. 2014. "Fact Sheet on new grandstands." Accessed 19th April. http://sydneycricketground.com.au/news/2014-ashes-media-kit/newgrandstands/fact-sheet-on-new-grandstands/.

Sarstedt, Marko, Christian Ringle, Sascha Raithel, and Siegfried Gudergan. 2014. "In Pursuit of Understanding What Drives Fan Satisfaction." Journal of Leisure Research 46 (4):419-447.

Savige, Gayle, Abbie MacFarlane, Kylie Ball, Anthony Worsley and David Crawford. 2007. "Snacking behaviors of adolescents and their association with skipping meals". International Journal of Behavioral Nutrition and Physical Activity 4 (36): 36.

Sporting Intelligence. 2013. "NFL remains by far the best attended domestic sports league in the world « Sporting Intelligence." Last Modified 4th January 2013 Accessed 7th January. http://www.sportingintelligence.com/2013/01/04/nflremains-best-attended-domestic-sports-league-in-the-world-040101/.

Sukalakamala, Piyavan, Sophitmanee Sukalakamala, and Pam Young. 2013. "An Exploratory Study of the Concession Preferences of Generation Y Consumers." Journal of Foodservice Business Research 16 (4): 378-390. doi: 10.1080/15378020.2013.824278.

Tarbert, Kristine. 2015. "High cost of hydration: Sports stadiums facing pressure to reduce food and drink prices." The Daily Telegraph, Last Modified March 3rd 2015 Accessed 20th July. http://www.dailytelegraph.com.au/newslocal/west/highcost-of-hydration-sports-stadiums-facing-pressure-to-reduce-food-and-drinkprices/story-fngr8i5s-1227245839561.

Tobin, Ben. 2013. "Stadium food is bottom of the league for sports fans." Last Modified December 19th 2013 Accessed 20th January. https://yougov.co.uk/news/2013/12/19/stadium-food-bottom-league-sports-fans/.

Veenhuyzen, Max. 2014. "Meat pie: a great Australian dish." The Guardian, Last Modified 7th May 2014 Accessed 20th July. http://www.theguardian.com/lifeandstyle/australia-food-blog/2014/may/07/meatpie-a-great-australian-dish. 
Wakefield, Kirk L, Jeffrey G Blodgett, and Hugh J Sloan. 1996. "Measurement and Management of the Sportscape." Journal of Sport Management 10 (1):15-31.

Wakefield, Kirk L, and Hugh J Sloan. 1995. "The Effects of Team Loyalty and Selected Stadium Factors on Spectator Attendance." Journal of Sport Management 9 (2): 153-172.

Wheaton, Belinda. 2007. "After Sport Culture." Journal of Sport \& Social Issues 31 (3): 283-307. doi: 10.1177/0193723507301049.

WHO (World Health Organisation) 2015. "Healthy diet”. Accessed $28^{\text {th }}$ January 2016. http://www.who.int/mediacentre/factsheets/fs394/en/.

Yancey, Antronette, David Winfield, Judi Larsen, Michele Anderson, Portia Jackson, Jeff Overton, Shawn Wilson, Allen Rossum, and Shiriki Kumanyika. 2009. "“Live, Learn and Play": Building strategic alliances between professional sports and public health." Preventive Medicine 49 (4): 322-325.

Yoshida, Masayuki, and Jeffrey D. James. 2011. "Service quality at sporting events: Is aesthetic quality a missing dimension?" Sport Management Review 14 (1): 1324.

Yusof, Aminuddin, and Hooi See Lee. 2008. "Sportscape features and team quality: implivation on spectators satisfaction and future attendance." Journal of Global Business Management 4 (2): 76-82.

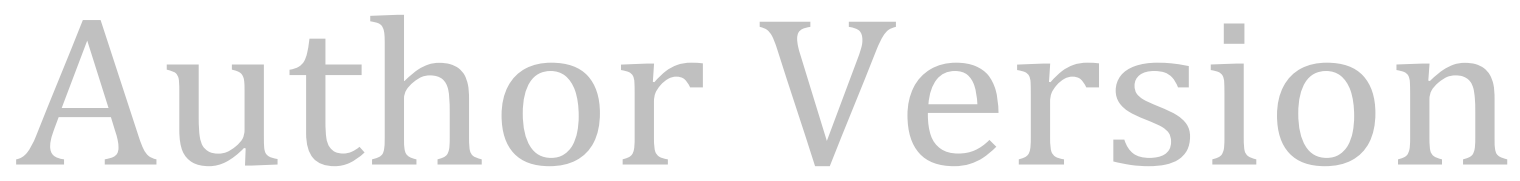

